\title{
Risk Factors of Recurrent Wheeze in Infancy
}

\author{
SAMIHA AMIN ${ }^{1}$, ARM LUTHFUL KABIR ${ }^{2}$
}

\begin{abstract}
Background: Recurrent wheeze in infancy is a common clinical problem and one of the most important causes of health facility visits in Bangladesh. Recurrent wheeze is an important manifestation of bronchiolitis, pneumonia and asthma.
\end{abstract}

Objectives: The study was conducted to identify the risk factors associated with recurrent wheeze in infancy.

Methods: This case control study was conducted at Dhaka Shishu Hospital and Dhaka Medical College Hospital (DMCH) during August 2008- June 2009 including 50 infants (1-12 months of age) with recurrent (3 or more) wheeze or wheeze persisting for more than one month during first year of life as study group and 50 children (12 months to 24 months of age) who had no wheeze during first year of life as control group

Results: The study group comprised of 34 (68.0\%) male and 16(32.0\%) female infants and control group included 31(62.0\%) male and 19 (38.0\%) female children. The mean age of study group was 9 months and that of the control group was 18 months. The median age of first attack of wheeze was 4 months. Twenty one (42.0\%) infants in study group and 29 (58.0\%) in control group were exclusively breastfed. On the other hand, 29 $(58.0 \%)$ studied cases and 21(42.0\%) controls were mixed fed (formula, cow's milk, suji along with breast milk). The study children who were exclusively breastfed had lesser incidence of recurrent wheeze than those who were mixed fed but the difference was not significant $(P>0.05)$. There was past history of bronchiolitis in $45(90.0 \%)$ cases of study group in comparison to only $3(6.0 \%)$ cases of control group $(p<0.05)$. Past history of pneumonia was present in $15(30.0 \%)$ cases of study group compared to only $3(6.0 \%)$ cases of control group $(P<0.05)$. There was history of mother's asthma among $14(28.0 \%)$ infants of study group versus only $1(2.0 \%)$ mother of control group $(P<0.05)$. There was history of father's asthma in $8(16.0 \%)$ cases of study group in comparison to none of control group $(P<0.05)$. In this study we observed that $11(22.0 \%)$ infants of study group had sibs suffering from wheeze compared to only $3(6.0 \%)$ children of control group $(<0.05)$. Sixteen (32.0\%) infants of study group versus only $6(12.0 \%)$ children of control group had atopic dermatitis and $33(66.0 \%)$ cases of study group had suffered from allergic rhinitis whereas only 10 (20.0\%) children had allergic rhinitis in control group $(P<0.05)$. Atopic dermatitis and allergic rhinitis among study children were significantly associated with recurrent wheeze during infancy. Twenty (40.0\%) study cases had exposure to tobacco smoke compared to $22(44.0 \%)$ cases of control group. Exposure to tobacco smoke was not found to be associated with recurrent wheeze $(P>0.05)$

Conclusion: The risk factors of recurrent wheeze in infancy identified in this study were past history of bronchiolitis, past history of pneumonia, asthma in parents (father and mother), wheeze in other sibs and atopic condition in children (atopic dermatitis, allergic rhinitis). Exclusively breastfed children had lesser incidence of recurrent wheeze than those who were mixed fed but the difference was not significant and exposure to tobacco smoke was not associated with recurrent wheeze in infancy in the present study.

Keywords: Risk factors, recurrent wheeze, infancy.

1. Child Specialist.

2. Professor of Pediatrics, Ad-din Medical College, Baro Moghbazar, Dhaka, Bangladesh.

Correspondence: Dr. Samiha Amin, Apt. 301, House 74, Road 8A, Dhanmondi R/A, Dhaka 1209, Bangladesh. E-mail: samiha_amin@yahoo.com

\section{Introduction}

Respiratory diseases in children are the major causes of hospital visits in Bangladesh. ${ }^{1}$ Wheeze during first year of life is a very frequent condition worldwide: $45 \%$ experience at least one episode and $23 \%$ experience recurrent wheeze. ${ }^{2,3}$ Recurrent cough and wheeze in 
infancy are common problems in general paediatric outpatient clinics and practice. ${ }^{4,5}$ Atopic conditions such as asthma, atopic eczema, allergic rhinitis are prevalent significantly among Bangladeshi children. ${ }^{6}$ Wheeze is an important manifestation of bronchiolitis, bronchial asthma, pneumonia and requires hospitalization in many cases. Family history of atopy, asthma, parental smoking are more common in wheezing infants. With this background this study was conducted to identify the risk factors associated with recurrent wheeze in infancy.

\section{Materials an Methods}

This is a case control study that was conducted at Dhaka Shishu Hospital and Dhaka Medical College Hospital (DMCH) during August 2008 to June 2009. Dhaka Shishu (Children) Hospital is the largest paediatric hospital of Bangladesh having about 600 inpatient beds and an Out Patient Department (OPD) catering 500-700 sick children daily. Dhaka Medical College Hospital (DMCH) is the premier medical college hospital of Bangladesh in which the paediatric inpatient department has 90 beds and Out Patient Department (OPD) has about 300-500 daily attendance. The study included 50 infants (1- 12 months of age) with recurrent ( 3 or more) wheeze or wheeze persisting for more than one month during first year of life, born with uneventful delivery who were thriving well ( weight for age $>3^{\text {rd }}$ centile) as study group and 50 children (12 months to 24 months of age) who had no wheeze during first year of life, born with uneventful delivery, hospitalized for reasons other than wheeze, who were thriving well ( weight for age $>3^{\text {rd }}$ centile) as control group. Both the cases and controls were selected from the outpatient and inpatient departments of above mentioned institutes. The cases were enrolled consecutively after taking informed consent from the parents. The studied infants and children who were admitted to the hospital had different reasons for hospitalization like bronchiolitis, pneumonia, febrile convulsion, diarrhea etc. A detail history was taken from care givers of all children including the sociodemographic characteristics such as age, sex, birth weight, gestational age season of birth, breast feeding, feeding practices, parent's education, socio-economic status, exposure to tobacco smoke and past history of lower respiratory tract infection (LRTI) like pneumonia and bronchiolitis, family history of asthma in parents and presence of wheeze in other sibs and atopic conditions in children themselves like atopic dermatitis, allergic rhinitis. Informed consent was taken from the parents of the patients before including their children in the study. All data were entered, checked, rechecked and scrutinized following standard procedure and analysed by SPSS programme.

\section{Results}

The study group comprised of infants from 1 month to 12 months of age and control group included children aged between 13 months to 24 months. The mean age of study group was 9 months and that of the control group was 18 months. The median age of first attack of wheeze was 4 months. Gestational age and birth weight was similar in both the groups. Educational, professional and economic background of parents were also similar in study and control group.

In the present study, $34(68.0 \%)$ cases were male in study group versus $31(62.0 \%)$ in control group and 16 $(32.0 \%)$ cases were female in study group versus 19 $(35.0 \%)$ in control group. About two third of the study children were male and remaining one third were female (Table-1). Evaluating the gestational age, term (e"37 wks) born babies were $45(90.0 \%)$ and preterm (<37 wks) born babies were $5(10.0 \%)$ in both the groups. In study group, $43(86.0 \%)$ cases weighed more than $2500 \mathrm{gm}$ and $44(88.0 \%)$ children of control group weighed more than $2500 \mathrm{gms}$ at birth whereas $7(14.0 \%)$ infants of study group weighed less than $2500 \mathrm{gms}$ at birth and $6(12.0 \%)$ children of control group weighed less than $2500 \mathrm{gm}$ at birth.

Table-I

Sex distribution of study and control children

\begin{tabular}{lcc}
\hline Gender & $\begin{array}{c}\text { Study group } \\
\mathrm{n}(\%)\end{array}$ & $\begin{array}{c}\text { Control group } \\
\mathrm{n}(\%)\end{array}$ \\
\hline Male & $34(68.0)$ & $31(62.0)$ \\
Female & $16(32.0)$ & $19(38.0)$ \\
\hline
\end{tabular}

Twenty one $(42.0 \%)$ infants in study group and 29 $(58.0 \%)$ in control group were exclusively breastfed. On the other hand, $29(58.0 \%)$ study cases and $21(42.0 \%)$ controls were mixed fed (formula, cow's milk, suji along with breast milk) (Table-II). The study children who were exclusively breastfed had lesser incidence of recurrent wheeze than those who were mixed fed but the difference was not significant $(P>$ 0.05). 
Table-II

Association between feeding practice and recurrent infantile wheeze

\begin{tabular}{lcccc}
\hline Feeding practice & $\begin{array}{c}\text { Study group } \\
\mathrm{n}(\%)\end{array}$ & $\begin{array}{c}\text { Control group } \\
\mathrm{n}(\%)\end{array}$ & $\begin{array}{c}\mathrm{P} \\
\text { value }\end{array}$ & $\begin{array}{c}\text { Odds ratio } \\
(95 \% \mathrm{Cl})\end{array}$ \\
\hline EBF & $21(42.0 \%)$ & $29(58.0 \%)$ & 0.109 & $0.52(0.22-1.25)$ \\
Mixed & $29(58.0 \%)$ & $21(42.0 \%)$ & & \\
\hline
\end{tabular}

(EBF: Exclusive breast feeding)

There was past history of bronchiolitis in 45 (90.0\%) cases of study group in comparison to only $3(6.0 \%)$ cases of control group. Past history of bronchiolitis was found to be significantly associated with recurrent infantile wheeze $(\mathrm{P}<0.05)$ (Table -III). There was past history of pneumonia in $15(30.0 \%)$ cases of study group compared to only $3(6.0 \%)$ cases of control group. Past history of pneumonia was also found to be significantly associated with recurrent infantile wheeze $(P<0.05)$ (Table -3). There was history of asthma among $14(28.0 \%)$ mothers of study group in comparison to only $1(2.0 \%)$ mother of control group. Most of the children (49/50;98.0\%) of control group didn't have a history of maternal atopy. History of maternal asthma is significantly associated with recurrent infantile wheeze $(P<0.05)$ (Table$3)$. There was history of father's asthma in $8(16.0 \%)$ cases of study group in comparison to none of control group. So history of parent's asthma was also significantly associated with recurrent infantile wheeze $(P<0.05)($ Table-3). In this study we observed that among $11(22.0 \%)$ cases of study group had recurrent wheeze in other sibs and only $3(6.0 \%)$ children of control group had recurrent wheeze in other sibs. Recurrent wheeze in other sibs in the family was also found to be significantly associated with recurrent wheeze in infancy $(P<0.05)$. (TableIII). Among the atopic conditions, $16(32.0 \%)$ infants of study group had atopic dermatitis whereas only 6 $(12.0 \%)$ children of control group had atopic dermatitis. Presence of atopic dermatitis was significantly associated with recurrent infantile wheeze $(P<0.05)$ (Table-III). Thirty three $(66.0 \%)$ cases of study group had suffered from allergic rhinitis whereas only $10(20.0 \%)$ children had allergic rhinitis in control group. Allergic rhinitis was significantly associated with recurrent wheeze in infancy $(P<$ $0.05)$ (Table-III). Twenty (40.0\%) study cases had exposure to tobacco smoke compared to $22(44.0 \%)$ cases of control group. Exposure to tobacco smoke was not found to be associated with recurrent wheeze $(P>0.05)$ (Table-III).

Table-III

Association of following risk factors with recurrent infantile wheeze

\begin{tabular}{lcccc}
\hline Risk factors & $\begin{array}{c}\text { Study group } \\
\mathrm{n}=50(\%)\end{array}$ & $\begin{array}{c}\text { Control group } \\
\mathrm{n}=50(\%)\end{array}$ & $\begin{array}{c}\mathrm{P} \\
\text { value }\end{array}$ & $\begin{array}{c}\text { Odds ratio } \\
(95 \% \mathrm{Cl})\end{array}$ \\
\hline PHO Bronchiolitis & $45(90.0)$ & $3(6.0)$ & 0.001 & $141(27.29-887.07)$ \\
PHO Pneumonia & $15(30.0)$ & $3(6.0)$ & 0.001 & $6.71(1.64-31.83)$ \\
Mother's asthma & $14(28.0)$ & $1(2.0)$ & 0.001 & $19.06(2.41-405.91)$ \\
Father's asthma & $8(16.0)$ & $0(00.0)$ & 0.002 & Undefined \\
Infantile wheeze in sibs & $11(22.0)$ & $3(6.0)$ & 0.021 & $4.42(1.03-21.63)$ \\
Atopic dermatitis & $16(32.0)$ & $6(12.0)$ & 0.015 & $3.45(1.11-11.17)$ \\
Allergic rhinitis & $33(66.0)$ & $10(20.0)$ & 0.001 & $7.76(2.88-21.49)$ \\
Tobacco smoke & $20(40.0)$ & $22(44.0)$ & 0.573 & $0.85(0.35-2.03)$ \\
\hline
\end{tabular}




\section{Discussion}

This case control study was undertaken to determine the risk factors associated with recurrent wheeze in first 12 months of life. This study was conducted on children having similar sociodemographic features. The mean age of study cases and controls were 9 months and 18 months respectively. This study has provided us with an opportunity to identify some of the risk factors of recurrent wheeze in infancy. The knowledge of risk factors is important to counsel the parents and necessary to be able to deliver better care to the infants attending with recurrent wheeze.

The present study found that more male infants experienced recurrent wheeze than females both in the study and control groups though the difference was not significant. A study in Chinese Taipei observed that majority of children with lower respiratory infections was boys. ${ }^{7}$ An European study also demonstrated that male sex was a significant risk factor for recurrent wheezing. ${ }^{8}$ Boys are more likely to have smaller airways for their lung size than girls and this potentially put them at increased risk for respiratory tract infection. ${ }^{9}$

Breast feeding has long been believed to be protective for recurrent wheeze among non-atopic children. ${ }^{10}$ This study also showed that children who were exclusively breast fed were more protected from recurrent wheeze. American academy of Pediatrics has recommended breast feeding to decrease the risk of lower respiratory tract disease in children. ${ }^{11}$ Exclusive breast feeding is protective for acute bronchiolitis and infants with RSV bronchiolitis who need hospitalization during the first episode will be most likely to have higher recurrence of wheezing episodes in the subsequent 12 months. ${ }^{12}$

The present study found that past history of bronchiolitis had a significant association with recurrent wheeze in infancy. Acute lower respiratory infection (ALRI) early in life has been implicated as a factor for adverse respiratory outcomes later in life. Pneumonia and bronchiolitis are important causes of Acute lower respiratory infection (ALRI) with wheezing. ${ }^{13,14}$ This study observed that personal history of atopic dermatitis and allergic rhinitis was significantly associated with recurrent infantile wheeze. Atopic wheezers are more likely to have a family history of asthma or a personal history of atopic dermatitis. ${ }^{15} \mathrm{~A}$ study in Bangladesh also showed that children below
2 years of age were 3.5 times more vulnerable to recurrent wheeze if they have allergic conjunctivitis and 4 times more vulnerable to recurrent wheeze if they have allergic rhinitis. ${ }^{16}$

In this study it was observed that presence of history of maternal asthma, paternal asthma, presence of wheeze in other sibs were significantly associated with recurrent wheeze in infancy. Wheeze in infancy is significantly associated with maternal asthma. ${ }^{17} \mathrm{~A}$ study in Latin America observed that maternal asthma and atopy are related to increased risk of developing bronchiolitis. ${ }^{12}$ An European study found that family history of atopy was a significant factor for bronchiolitis and wheezing. ${ }^{18} \mathrm{~A}$ study from USA revealed that risk of bronchiolitis among infants born to mothers who had both asthma and smoking habit during pregnancy was at $50 \%$ greater risk than that of infants with neither risk factors. ${ }^{19}$ Maternal asthma and atopy were more frequently observed in cases of bronchiolitis than in controls in a study in UK. ${ }^{19}$ Parental history of asthma increases the risk of developing lower respiratory infection in early life. ${ }^{20} \mathrm{~A}$ case control study in Gambia where the prevalence of asthma is much lower than in UK showed that maternal asthma was associated with RSV bronchiolitis in infants. ${ }^{21}$ The present study didn't find significant association between environmental smoke exposure (tobacco smoke) and recurrent wheeze in infancy. Passive smoking has frequently been reported as a risk factor for respiratory infection in children. ${ }^{22}$ A meta analysis from Australia provided strong evidence that exposure to environmental tobacco smoke causes adverse respiratory health outcomes and confirms that the child of a parent who smokes is at approximately twice the risk of having a serious lower respiratory infection, this association was very pronounced in children younger than two years of age..$^{23}$

The risk factors of recurrent wheeze in infancy identified in this study were past history of bronchiolitis, past history of pneumonia, history of father's and mother's asthma, presence of atopic conditions like atopic dermatitis, allergic rhinitis in children and presence of wheeze in other sibs. Exclusively breastfed children had lesser incidence of recurrent wheeze than those who were mixed fed but the difference was not significant and exposure to tobacco smoke was not associated with recurrent wheeze in infancy in the present study. 


\section{References}

1. Kabir ARML, Amin MR, Mollah MAH, Khanam S, Mridha AA, Ahmed S, et al. Respiratory Disorders in Under-Five Children Attending Different Hospitals of Bangladesh: A Cross Sectional Survey. Journal of Respiratory Medicine Research and Treatment. 2016(2016); Article ID 183615, DOI: $10.5171 / 2016.183615$

2. Mallol J, Garcia-Marcos L, sole D, Brand P. International prevalence of recurrent wheezing during the first year of life: variability,treatment patterns and use of health resources. Thorax. 2010;65:1004-1009.

3. Garcia-Marcos L, Mallol J, sole D, Brand PL. EISL Study Group. International study of $t$ wheezing in infants: risk factors in affluent and non-affluent countries during the first year of life. Paediatric Allergy Immunol. 2010; 21:878-88.

4. Park ES, Golding J, Carswell F, Stewart Brown S. Preschool wheezing and prognosis at 10. Arch Dis Child. 1986;61: 642-46.

5. Martinez FD, Wright AL, Taussig LM, Holberg CJ, Halonen M, Morgan WJ, et al Asthma and wheezing in the first six years of life. $\mathrm{N}$ Eng $\mathrm{J}$ Med. 1995 ;332: 133-38.

6. Kabir ARML, Rahman F,Hassan MQ, Ahmed F, Mridha MA. Asthma, atopic eczema and allergic rhino - conjunctivitis in school Children. Mymen Med Jour. 2005;14:3-5.

7. Lin HC, Hwang KC, Yang YH, Lin YT, Chiang $B L$. Risk factors of wheeze and allergy after lower respiratory tract infections during early childhood. J Microbiol Immunol Infect. 2001; 34: 259-64.

8. Halken S, Host A, Husby S, Hansen LG, Osterballe $\mathrm{O}$, Nyboe J. Recurrent wheezing in relation to environmental risk factors in infancy. Allergy. 1991; 46: 507-14.

9. Martinez FD, Morgan WJ, Wright AL, Holberg $C$, Taussig LM. Initial airway function is a risk factor for recurrent wheezing respiratory illnesses during the first three years of life. Group Health Medical Associates. Am Rev Respir Dis. 1991; 143: 312-6.
10. Rosa MPG, Javier M, Dirceu S, Paul LP, Virginia PF, Manuel SS, Luis GM \& the EISL Study Group. Factors associated with the time to the first wheezing episode in infants: a crosssectonal study from the international study of wheezing in infants (EISL). npj Primary Care Respiratory Medicine 26, Aritle Number: 15077 (2016). doi: 10.1038/npjpcrm.2015.77

11. Fonseca Cde B, Grisi S. Bronchiolitis , respiratory syncytial virus, and recurrent wheezing : what is the relationship? Rev Hosp Clin Fac Med Sao Paulo. 2003; 58 : 39-48.

12. Cifuentes $\mathrm{LI}$, Caussade $\mathrm{S}$, Villagran $\mathrm{C}$ et al. Risk factors for recurrent wheezing following acute bronchiolitis: A 12 month follow up. Pediatr Pulmonol. 2003; 36:316-21.

13. Yau KI Fang LJ, Shieh KH. Factors predisposing infants to lower respiratory infection with wheezing in the first two years of life. Ann Allergy Asthma Immunol. 1999 ; $82: 165-70$.

14. Reijonenz TM, Korppi M, Kleemola M, et al. Nasopharyngeal eosinophil cationic protein in bronchiolitis: relation to viral findings and subsequent wheezing. Pdiatr Pulmonol. 1997; 24: 35-41.

15. Bisgaard H, Dalgaard P, Nyboe J. Risk factors for wheezing during infancy. A Study of 5,953 infants. Acta Pediatr Scand. 1987; 76 : 719-26.

16. Hossain MD. Risk factors of recurrent wheeze in first 24 months of life. Dissertation, BCPS, Dhaka. 2004; p 71-77.

17. Duff AL, Pomeranz ES, Geller LE, et al. Risk factors for acute wheezing in infants and children: viruses, passive smoking, and $\lg E$ antibodies to inhalant allergens. Pediatrics. 1993; 92:535-40.

18. Reijonen TM, Korpi M. One year follow up of young children hospitalized for wheezing: The influence of early anti inflammatory therapy and risk factors for subsequent wheezing and asthma. Pediatr Pulmonol. 1998;26 : 113-119.

19. Kecia N, Carrol T, Gebretsadik T, Griffin MR, Dupont WD, Mitchel EF, et al. Maternal asthma and maternal smoking are associated with 
increased risk of Bronchiolitis during infancy. Peditr. 2007: 119; 1104-1112.

20. Bosken $\mathrm{CH}$, Hunt $\mathrm{W}$, Lambert $\mathrm{W}$ et al. $\mathrm{A}$ parental history of asthma is a risk factor for wheezing and non wheezing respiratory illness in infants younger than 18 months of age. Am J Respir Crit Care Med. 2000; 161: 1810-1815.

21. Weber MW, Milligan $P$, Hilton S, et al. Risk factors for severe RSV infection leading to hospital admission in children in the western region of Gambia. Int J Epidemiol. 1999; 28: 157-162.
22. Strachan DP, Cook D. Health effects of passive smoking : Parental smoking and lower respiratory illnesses in infancy and early childhood. Thorax. 1997; 52: 905-14.

23. Janet SM, Jennifer KP, Xuan W, Berry G. Meta analysis on the association between environmental tobacco smoke exposure and the prevalence of lower respiratory tract infection in early childhood. Pediatr Pulmonol. 1999; 27: 5-13. 